\title{
Demographics of the Society for Range Management
}

\section{A 2002 survey provides some interesting - and perhaps surprising - results about SRM membership.}

\section{By Samuel W. Albrecht}

The October 1992 edition of Rangelands ran an article titled "SRM - WHO WE ARE: A First Look at the Demographic Data" by Ray Housley and Rene Crane. That piece gave a good snapshot of the diversity in our membership. Jump forward about ten years and we have run the numbers again.

This piece will report the results of the 2002 survey of the membership. Many of the same questions were asked in 2002 as were asked in 1992. We again will use the same caveat that was used in 1992, "while the raw data presented here carry no guarantees of statistical reliability, they provide some interesting - and perhaps surprising - facts."

The survey was mailed to all current members and over 1,215 (approximately $30 \%$ ) returned the survey by fax, mail, or completed the information online. In 1992, 53\% of the membership participated.

The first question examined is who do we work for. Figure 1 shows that we are a very diverse group. When

SRM Membership by Profession

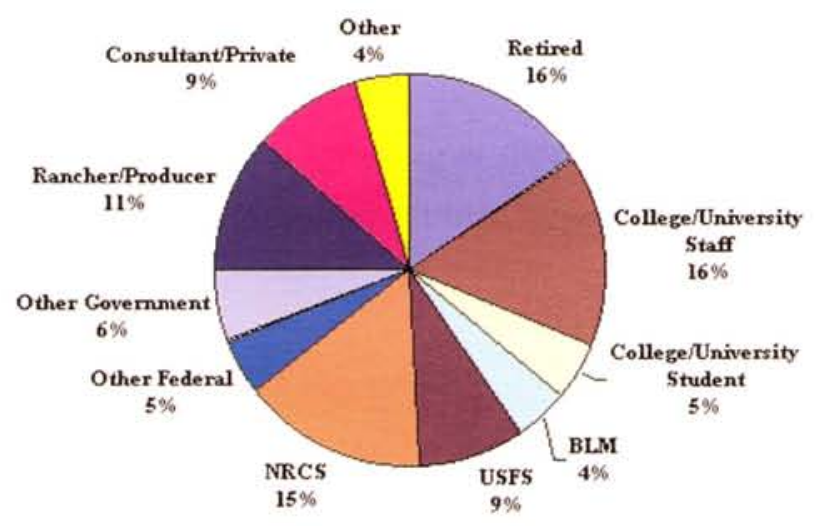

we look at the differences between 1992 and 2002 in Figure 2, we see some changes in the different profession-

1992 vs 2002 SRM Membership by Profession

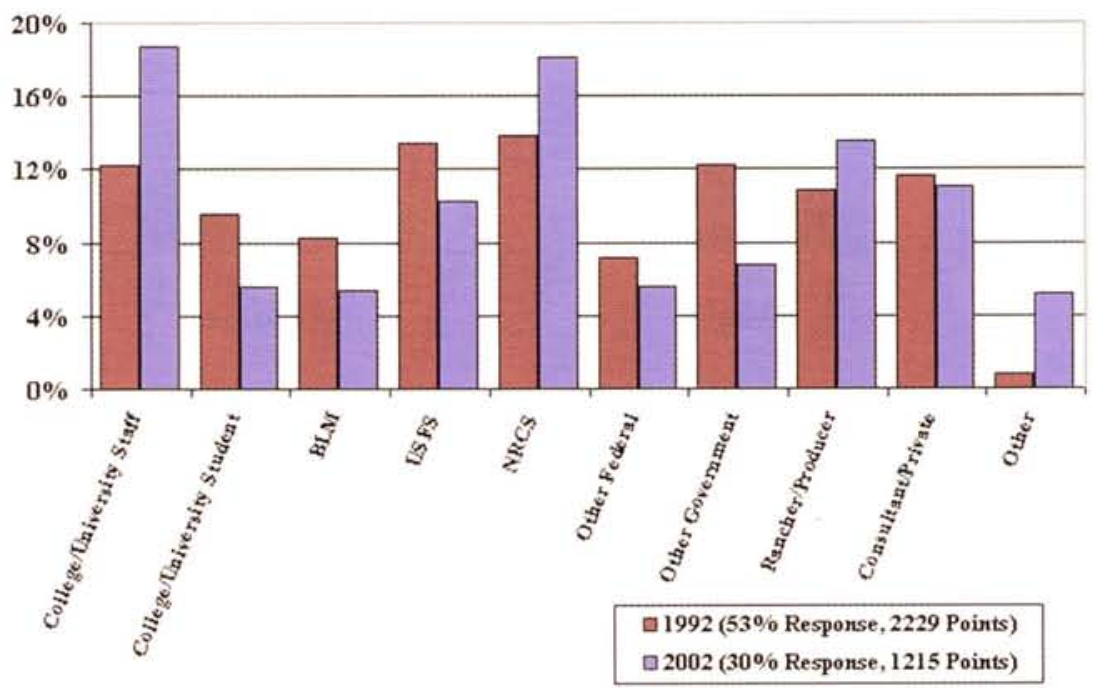


al groups. The biggest change is a $6 \%$ increase in the College/University Staff category.

If we look at ethnicity, Figure 3, we are $91.6 \%$ Caucasian, a decrease from $94 \%$ in 1992 . The change in percentage among non-Caucasian between 1992, and 2002 was very small.

\section{SRM Membership by Ethnicity}

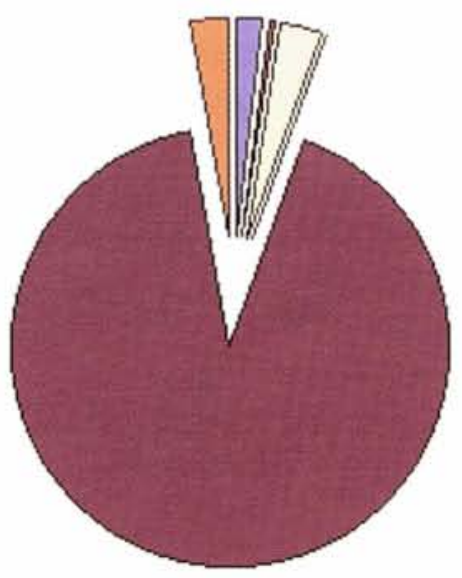

Hispanic - $2.0 \%$

Asian - $0.5 \%$

$\square$ Native American - 2.9\%

$\square$ Black - $0.2 \%$

Caucasian - $91.6 \%$

Other $-2.8 \%$

Another slowly shifting change in membership is gender. Figure 4 shows a greater than $6 \%$ increase in female membership between 1992 and 2002.

1992 vs 2002 SRM Membership by Gender

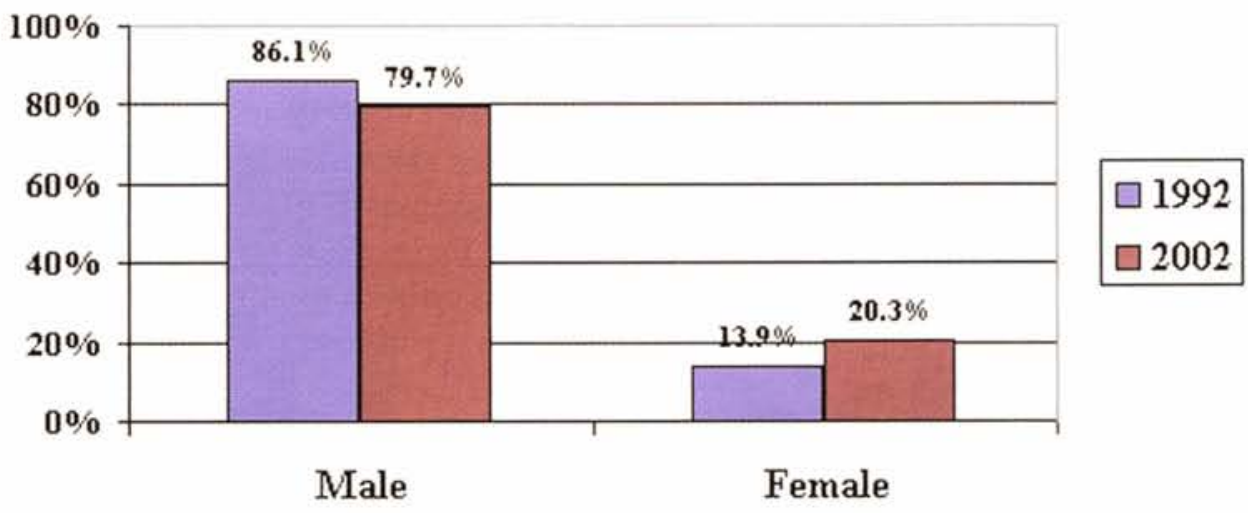




\section{SRM Demographics By Decade of} Birth

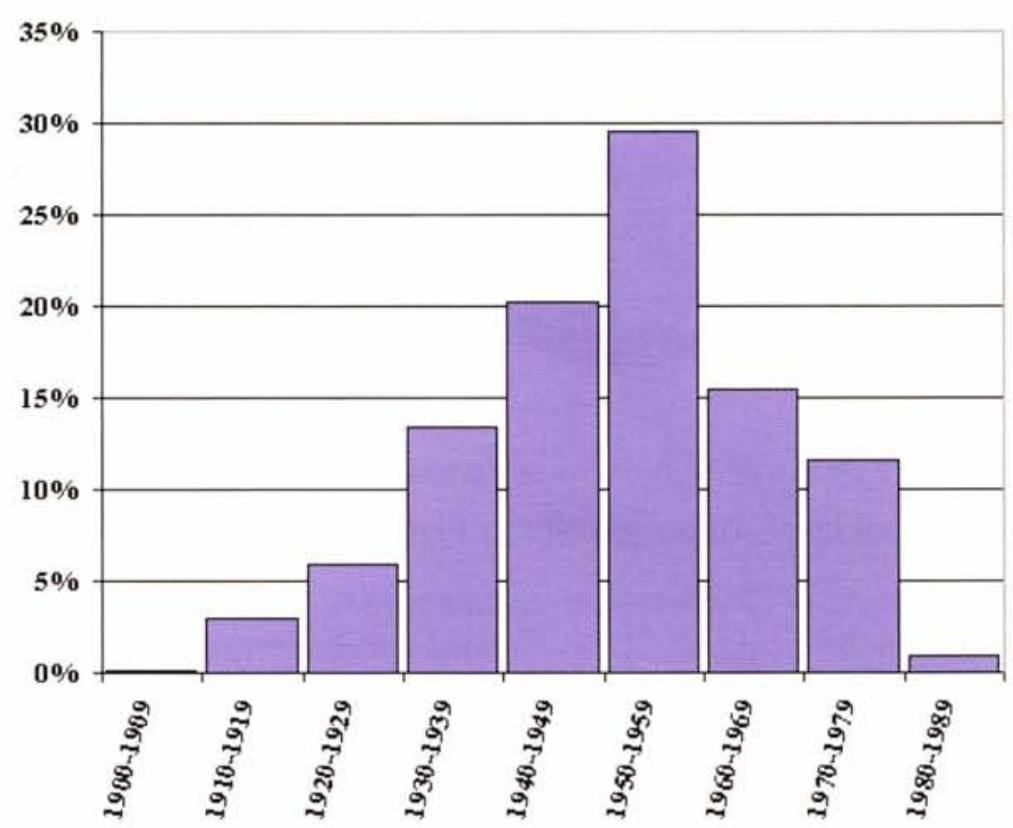

As we started looking at this shift in gender, we also started wondering about the overall age of our membership. Figure 5 shows the age of our members by their decade of birth. When you further sort that data by gender, Figure

\section{SRM Demographics - Males/Females by Decade of Birth}

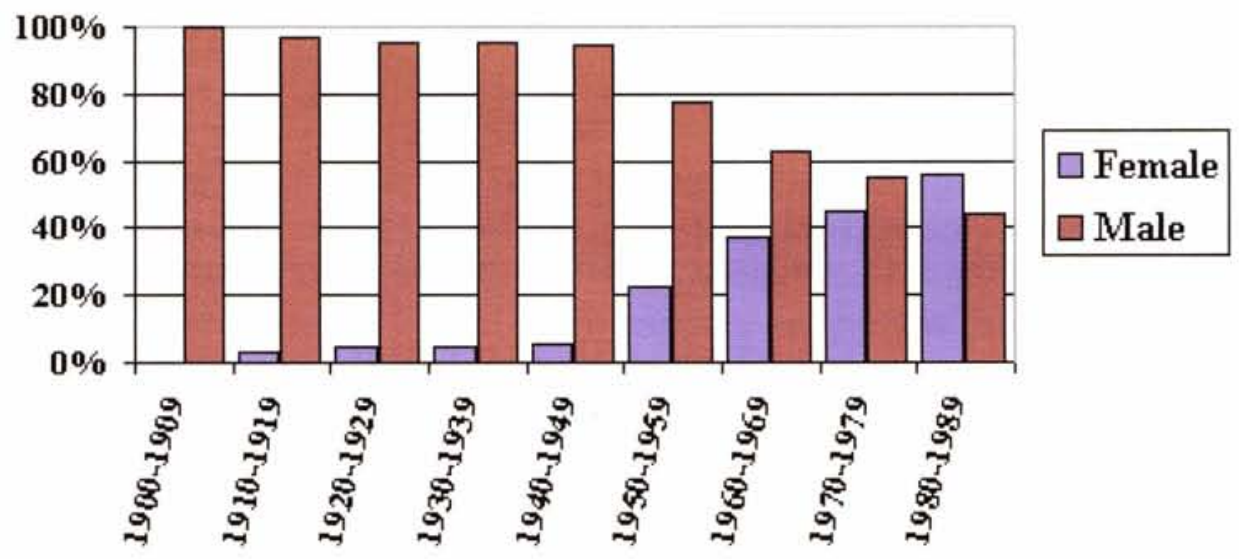

6 provides a very interesting visual showing the greatly increasing number of young, female members of our Society. 


\section{SRM Membership by Education}

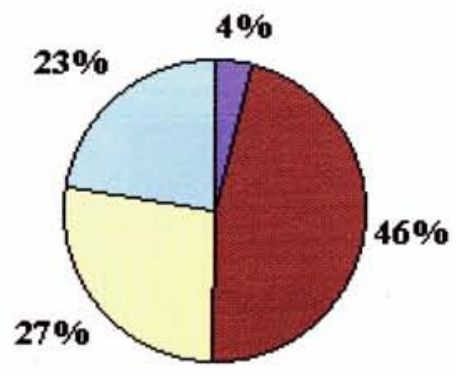

$\square$ High School
$\square$ Bachelors
$\square$ Masters
$\square$ Doctorate

We also looked at the educational levels of our members. Figure 7 shows the 2002 data and Figure 8 provides a comparison to 1992 .

1992 vs 2002 SRM Membership by Higher Education

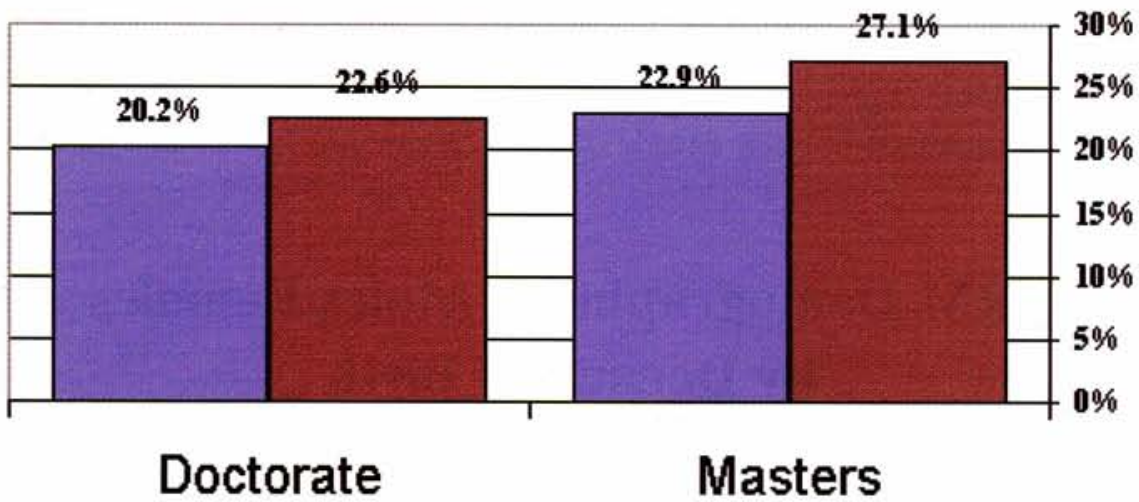

$\square 2002 \square 1992$

This information is being used by our leadership to tweak our Strategic Plan and our Communication and Marketing Plan. I hope we do not wait another ten years to run this exercise again. 